\title{
The Efficacy of Financial Futures as a Hedging Tool in Electricity Markets
}

Jim Hanly

Technological University Dublin, james.hanly@tudublin.ie

Lucia Morales

Technological University Dublin, lucia.morales@tudublin.ie

Damien Cassells

Technological University Dublin, damien.cassells@tudublin.ie

Follow this and additional works at: https://arrow.tudublin.ie/buschacart

Part of the Corporate Finance Commons, and the Engineering Commons

\section{Recommended Citation}

Hanly, J., Morales, L. \& Cassells, D. (2018). The Efficacy of Financial Futures as a Hedging Tool in Electricity Markets. International Journal of Finance \& Economics, vol. 23, no. 1, pp. 29-40. doi: 10.1002/ ljfe.1600.

This Article is brought to you for free and open access by the School of Accounting and Finance at ARROW@TU Dublin. It has been accepted for inclusion in Articles by an authorized administrator of ARROW@TU Dublin. For more information, please contact arrow.admin@tudublin.ie, aisling.coyne@tudublin.ie, gerard.connolly@tudublin.ie. 
The Efficacy of Financial Futures as a Hedging Tool in Electricity Markets

Jim Hanly ${ }^{a}$, Lucia Morales ${ }^{b}$, Damien Cassells ${ }^{c}$

ajim Hanly,

College of Business,

Dublin Institute of Technology,

Dublin 2,

Ireland.

Tel +3531402 3180,

E-mail james.hanly@dit.ie.

Corresponding Author.

${ }^{\mathrm{b}}$ Lucia Morales,

College of Business,

Dublin Institute of Technology,

Dublin 2,

Ireland.

Tel +3531402 3230,

E-mail lucia.morales@dit.ie.

${ }^{\mathrm{c}}$ Damien Cassells,

College of Business,

Dublin Institute of Technology,

Dublin 2,

Ireland.

Tel +353 1402 7153,

E-mail damien.cassells@ dit.ie. 


\begin{abstract}
This paper estimates and applies a risk management strategy for electricity spot exposures using futures hedging. We apply our approach to three of the most actively traded European electricity markets, Nordpool, APXUK and Phelix. We compare both optimal hedging strategies and the hedging effectiveness of these markets for two hedging horizons, weekly and monthly using both Variance and Value at Risk (VaR). Our key finding is that electricity futures can effectively manage risk only for specific time periods when using hedging strategies that have been very successful in financial and other commodity markets. More generally they are ineffective as a risk management tool when compared with other energy assets. This is especially true at the weekly frequency. We also find significant differences in both the Optimal Hedge Ratios (OHR's) and the hedging effectiveness of the different electricity markets. Better performance is found for the Nordpool market, while the poorest performer in hedging terms is the Phelix market.
\end{abstract}

Keywords: Hedging; Risk Management, GARCH, Electricity Futures.

JEL classification: G10, G12, G15. 


\section{INTRODUCTION}

Following the deregulation and liberalisation of electricity markets in Europe, several power markets exchanges now facilitate the trading of electricity. This process has resulted in power companies shouldering the risk of adverse price movements as regulators no longer automatically allow them to transfer risk to their customers through price increases. In turn this has generated a demand for derivative products to allow for hedging those price risks. Hedging with futures contracts has become a standard way of managing commodity price risk, particularly with reference to energy markets, and standardised futures contracts are now traded on many power exchanges.

A large literature has documented the use and effectiveness of futures as a hedging tool since early work by Ederington (1979). This literature has examined equities (Cotter and Hanly, 2012, Kanas, 2009), various commodities (Chen and Sutcliffe, 2012, Wu, Guan, and Myers, 2011), foreign exchange (Kroner and Sultan, 1993, Röthig, 2011) portfolio products such as exchange traded funds (Alexander and Barbosa, 2008) and energy commodities such as Crude oil and Natural Gas, (see for example, Chang, McAleer and Tansuchat, 2011, Brinkmann and Rabinovich, 1995, Fraser and McKaig, 2000). The general results from the literature are that hedging is generally very effective as measured by risk reductions of the order of $60 \%-90 \%$ depending on the underlying asset being hedged. Some assets have shown better hedging effectiveness, notably stock indices and certain oil contracts such as West Texas Intermediate which have shown hedging effectiveness above $95 \%$ in some instances.

There has been relatively little work which has examined electricity price hedging using futures within the European context as the power exchanges are still relatively new ${ }^{1}$. Another reason is that there are challenges associated with electricity spot price modelling given the characteristics of electricity prices such as high volatility and price spikes which arise because of non-storability and seasonality (Wickens and Wimschulte, 2007, Botterud, Kristiansen, and Ilic, 2010, Xiao, Colwell and Barr, 2014).

One of the first papers to look at electricity futures hedging was Tanlapco, Lawarrée and Liu (2002). They looked at both cross and direct hedging using data from the US electricity market. They estimated optimal hedge ratios (OHRs) in the range 0.25 to 1.35 and found a significant difference between the Naïve hedge ratio and the OHR as estimated using OLS.

\footnotetext{
${ }^{1}$ The oldest exchange Nordpool was established in 1996, with APXUK and EEX more recent again in 1999 and 2002 respectively.
} 
They found reductions in risk as measured by the standard deviation ranging from about $3 \%$ up to a maximum of $38 \%$ depending on the market being hedged. Bystrom (2003) looked at hedging in the Nordpool market using weekly data, for the period $1996-1999$. He found that hedging effectiveness from Naïve (1:1 ratio), OLS and GARCH models was typically of the order of $10 \%-20 \%$. He also found that for specific periods or models hedging effectiveness was as high as $29 \%$ but also noted that there were cases where hedging actually increased the variance. Zanotti, Gabbi and Geranio (2010) use similar methods to analyse hedging for Nordpool, Phelix and Powernext markets. Their findings which are based on daily data indicate that model choice has a significant impact on hedging efficiency. They also find that daily hedges are relatively ineffective with typical variance reductions of around $2 \%-3 \%$. Frestad (2012) also analyses hedging in the Nordpool market but uses a more extensive dataset ranging from 2000 - 2010. Using an OLS model and a moving window to allow for time variation he documents relatively poor performance using a measure based on accumulated gain but notes that this may relate to ambiguity about the goals of a hedging strategy whereby risk minimisation may not be the main objective. More recently Sanda, Olsen and Fleten, (2013) look at company level hedging for hydro based electricity companies and find that over $90 \%$ of aggregate production is hedged. They use cash flow at risk rather than the variance as their measure of hedging efficacy and find that only one of twelve companies showed a significant reduction in monthly cash flow variance.

Given the lack of depth in terms of coverage of electricity hedging we address some issues that are pertinent. A key contribution of this paper is that we examine the efficacy of electricity futures markets within the context of the existing literature of futures hedging. We do this by applying proven futures based hedging strategies that have shown good performance when applied within other energy markets. Our key contribution over the existing literature is that we track the time varying performance of electricity futures hedges period by period using data at two frequencies, weekly and monthly. This allows us to focus on where hedging strategies are effective and where they show poor performance. This is important given the existing work in this area has reported hedging effectiveness as an average of many hedges and this has tended to underestimate the efficacy of electricity futures hedges. Our approach also allows us to track how OHR's and hedging effectiveness have changed as the markets have developed through both tranquil and intensely volatile periods. This paper also contributes by drawing comparisons from the broader hedging literature using both the commonly applied variance reduction criterion as well a downside risk measure - Value at Risk, to account for non-normality. Finally, we look at whether model choice matters in terms of hedging effectiveness. 
Our key result indicates that electricity market participants can only obtain good results on a period by period basis but that they can obtain only relatively minor risk reductions on average when compared with other energy or financial market participants. This result raises some questions about the raison d'etre of electricity futures markets given that the major justification for futures markets is their ability to offer risk management opportunities to market participants. We now outline the hedging models used in this paper.

\section{METHOD}

There are a number of frameworks that can be used to examine optimal hedging. The most generally applied is the variance minimisation framework (see for example, Ederington, 1979, Alexander and Barbossa, 2008,) which assumes that futures prices are martingales and hence ignores the return component of a hedged portfolio. In this framework the OHR is the ratio of futures relative to spot that minimises the variance of the hedged portfolio. Other papers have incorporated expected return into the estimation of the optimal hedge via utility maximisation (deVille deGoyet, Dhaene and Sercu, 2008). This allows a number of different characterisations of investor utility to be applied. In this paper we adopt the variance minimisation approach given the widespread use of the variance as a risk measure; its dominance in the hedging literature and its twin advantages of relative ease of calculation and interpretation. It also allows us to draw comparisons between the hedging effectiveness of electricity futures and the hedging effectiveness of other assets which many papers (see for example, Chang, McAleer and Tansuchat, 2011, Chen and Sutcliffe, 2012) have examined using the variance minimisation paradigm.

We use two methods to estimate the OHR. The first model we use is an OLS regression based hedge which yields a constant hedge ratio over the period for which it is estimated. This is given by:

$$
r_{s t}=\alpha+\beta r_{f t}+\varepsilon_{t}
$$

where $r_{s t}$ and $r_{f t}$ are the spot and futures returns respectively for period t. The OLS model has been extensively used since it was first applied to futures markets by Ederington (1979); however it assumes a constant variance despite evidence that many economic time series are heteroskedastic. GARCH models following Bollerslev (1986), address this issue by allowing the conditional distribution of spot and futures returns to vary over time. Therefore, the second model we use is the Constant Correlation or CCGARCH model introduced by 
Bollerslev $(1990)^{2}$. This model has been applied extensively in a hedging context, is easy to estimate and provides good estimation characteristics even for relatively small samples which is a useful characteristic where monthly data are being used as there are relatively few data points. The model is specified as follows:

$$
\begin{gathered}
y_{t}=E\left(y_{t} \mid F_{t-1}\right)+\varepsilon_{t}, \varepsilon_{t}=D_{t} \eta_{t} \\
\operatorname{var}\left(\varepsilon_{t} \mid F_{t-1}\right)=D_{t} R D_{t}
\end{gathered}
$$

where $y_{t}=\left(y_{1 t} \ldots y_{m t}\right)^{\prime}, \eta_{t}=\left(\eta_{1 t} \ldots \eta_{m t}\right)^{\prime}$ is a sequence of independent and identically distributed random vectors, $F_{t}$ is the information set at time t, $D_{t}=\operatorname{diag}\left(h_{1}^{1 / 2}, \ldots h_{m}^{1 / 2}\right), m$ is the number of returns and $t=1 . . n . R=E\left(\eta_{t} \eta_{t}^{\prime} \mid F_{t-1}\right)=\left(\eta_{t} \eta_{t}^{\prime}\right)$ where $R=\rho_{i j}$ for $i, j=1, \ldots, m . \varepsilon_{t} \varepsilon_{t}^{\prime}=D_{t} \eta_{t} \eta_{t}^{\prime} D_{t}$ $D_{t}=(\operatorname{diag} Q)^{1 / 2}$ and $E\left(\varepsilon_{t} \varepsilon_{t} \mid F_{t-1}\right)=Q_{t}=D_{t} R D_{t}$ where $Q_{t}$ is the conditional covariance matrix. The model assumes that conditional correlations are constant and therefore the conditional covariances are proportional to the product of the corresponding conditional standard deviations. Each of the conditional variances in $D_{t}$ has a univariate $\operatorname{GARCH}(1,1)$ specification.

$$
h_{i t}=\omega_{i}+\sum_{j=1}^{r} \alpha_{i j} \varepsilon_{i}^{2},_{t-j}+\sum_{j=1}^{s} \beta_{i j} h_{i, t-j}
$$

\subsection{Risk Measures}

We use two risk measures to compare the effectiveness of the OLS and CCGARCH hedge strategies. The first risk measure is the variance and the hedging effectiveness is measured as the percentage reduction in the variance of a hedged portfolio as compared with the variance of an unhedged portfolio which is simply the unhedged spot return.

$$
\% \text { Variance_Reduction }=1-\left[\frac{\text { VARIANCE } E_{\text {HedgedPorfolio }}}{\text { VARIANCE } E_{\text {UnhedgedPortolio }}}\right]
$$

Despite its broad ranging use, a key problem with the Variance as a risk measure, is that it cannot differentiate between upside and downside risk, as it gives equal weight to positive and negative returns. Given that electricity time series are non-normal as evidenced by skewness and kurtosis characteristics we have also included a downside risk metric to

\footnotetext{
${ }^{2}$ We also estimated a Naïve or 1:1 model but it underperformed the OLS model in all cases. Also, alternative parameterisations of the GARCH family of models were applied including the DCC GARCH model (Engle, 2002). We report the best performing model which is the CC GARCH model, but our other results are available on request.
} 
measure hedging effectiveness. There are a number of risk metrics that have the ability to measure risk in one tail of the distribution including Lower Partial Moments, Semi Variance and Expected Shortfall, however we have chosen to use VaR given its broad application in the regulatory framework, ease of estimation and intuitive interpretation. VaR estimates the maximum expected loss for a given confidence level and for a specified time period. The $\mathrm{VaR}$ at confidence level $\alpha$ is

$$
\operatorname{VaR}_{\alpha}=q_{a}
$$

where $q_{a}$ is the quantile of the loss distribution. We calculate VaR using the $5 \%$ confidence level. The performance metric employed is the percentage reduction in VaR.

$$
\% \text { VaR_Reduction }=1-\left[\frac{V a R_{5 \% \text { HedgedPortfolio }}}{V a R_{5 \% \text { UnhedgedPortfolio }}}\right]
$$

\section{DATA AND DESCRIPTIVE STATISTICS}

Electricity markets are very different from other energy commodities markets because of the non-storability of electricity. Spot markets for electricity are generally managed by Power Exchanges and prices are set by a process whereby bids are submitted by market participants for the day following the bid process. Equilibrium is established and a market clearing price is set for the following day and for this reason, spot markets are in effect day ahead markets. Electricity spot prices exhibit a number of key characteristics including volatility clustering, mean reversion, price jumps or spikes and seasonality. The demand and supply characteristics of the electricity market can change rapidly and therefore seasonal factors such as time of day, calendar, weather, and economic activity will all have an impact. Because these factors are time dependent, the frequency of the data will have an important impact on the price behaviour. Some of these characteristics present a unique challenge in terms of obtaining an efficient hedging solution to electricity price risk.

In this paper we are seeking to determine the efficacy of hedging as a risk management strategy for electricity market participants. Our analysis is also focused on the volatility characteristics of the European Electricity futures markets and the evolution of these markets which are still quite new as compared with longer established energy commodity markets. We therefore choose three different contracts to represent three different markets. The markets used are Nordpool for Scandinavia, European Energy Exchange for 
Germany (Phelix) and Amsterdam Power Exchange (APX) UK for the United Kingdom. These were chosen given their liquidity ${ }^{3}$ and because they are some of the most long standing electricity futures contracts available. In each case we obtained day-ahead auction prices which we use as spot prices. Note that the spot market for physical delivery of electricity is different than for other commodity markets and is based on an auction system that matches bids with generation and sets a price for market participants 24 hours prior to the delivery. Therefore spot prices are in effect a day-ahead futures contract ${ }^{4}$. For the futures contracts we used base load average reference prices for which a continuous series was formed using a rollover process. Our full sample is for a 10 year period and includes data from 15/09/2004 to 10/01/2014.We include data at two different frequencies; weekly (5-day) and monthly (20day) to allow for a broad ranging analysis that reflects the time horizons of different market participants. Descriptive statistics are given in Table 1.

[Table 1 here]

Each series displays a positive mean for the period under study. The electricity price data also shares many of the same characteristics of other energy series such as the presence of significant Skewness and Kurtosis. The Jarque-Bera (J-B) statistic indicates that each of the series is non-normal but also that departures from normality are more pronounced for higher frequency data. Indeed the descriptive statistics in general show that electricity spot prices tend to be much more volatile and have larger departures from normality than other financial, commodity, or energy assets. For example, weekly standard deviations are in the range $15 \%$ to $30 \%$ as compared with a typical weekly standard deviation for crude oil of about $5 \%$ or $2.5 \%$ for equities. This presents a particular challenge from a hedging perspective. Unit root tests indicate that all series are stationary while we also find the presence of significant ARCH effects in most cases. Also of interest is that while the correlation between spot and futures prices ranges from $70 \%$ to $90 \%$ depending on the electricity market, the attendant returns show much lower correlation. We also note that the correlations are higher at lower frequency indicating that hedging performance should be significantly better for lower frequency hedges.

\footnotetext{
${ }^{3}$ Liquidity on all three contracts has grown substantially since their inception and the open interest ranges from $1-10$ terawatt hours (TWH) per day.

${ }^{4}$ See the following for more detailed information: http://www.apxgroup.com/trading-clearing/apx-power-uk/ http://www.nordpoolspot.com/How-does-it-work/Day-ahead-market-Elspot-/ https://www.eex.com/en/products/power/power-derivatives-market
} 


\subsection{Estimation Procedure}

Our in-sample period is from 14/09/2005 to 05/09/2012. For this period we estimated a constant hedge ratio using OLS and a time-varying hedge ratio using the CCGARCH model. The spot return was then hedged using the following

$$
+r_{s t}-\beta r_{f t}
$$

where $r_{s}$ and $r_{f}$ are spot and futures returns respectively, and $\beta$ is the OHR. In this way we generated 368 t-period hedges in-sample at the weekly frequency and 92 at the monthly frequency for the period October 2005 to December 2012, these were formed into a single portfolio on which we based our hedging effectiveness estimates. We also retained a subsample of two years of data for the period 12/09/2012 to 01/10/2014 for out-of-sample testing. This was done by generating 1-step ahead forecasts of the OHR for use in period $t+1$. The OHR's were assumed to follow a random walk process and the 1-step-ahead forecasts for the time varying hedges were generated using a rolling window approach. Because we also wish to track how hedging effectiveness changed over time, we carried out an additional estimation based on a rolling window OLS model. The initial OHR was estimated using a window length equivalent to one year of data for the period October 2004 to October 2005 . The hedging effectiveness was then estimated for this portfolio of returns using the \% reduction in the variance criterion before rolling the window forward. This was done by adding an observation and removing the oldest observation thus keeping the window length unchanged. The process was then repeated. In this way we obtained 368 hedged portfolios at the weekly frequency (92 monthly) each with a different estimate of hedging effectiveness.

\section{EMPIRICAL RESULTS}

In this section we report our empirical findings. We first look at volatility of the different electricity markets and discuss the key determinants that contribute to this. We next look at the optimal hedging strategies as obtained from our models. Finally, we examine the hedging efficacy for the different markets and strategies.

\subsection{Volatility}

Results of our volatility analysis are presented in Table 2, while Figure 1 illustrates the volatility graphs obtained from fitting a $\operatorname{GARCH}(1,1)$ to the electricity return series. The most obvious difference is the large difference in the magnitude of volatility between spot 
and futures markets. For other financial assets these would typically mirror each other however for electricity the spot volatility is notably higher for the reasons discussed earlier. In terms of a comparison, some differences emerge across the different spot series, most notably the Nordpool series is the least volatile, followed by APXUK and PHELIX. Differences in spot volatility probably reflect the production structure and generational fuel mix in each market. For example, Norway has a very large hydro generation capacity which is relatively flexible whereas the German market has relied on both nuclear and coal fired generation which in less flexible and therefore more prone to spikes. An additional cause of volatility in the German market is the unpredictable behaviour caused by the massive recent installation of renewables such as wind and solar and their attendant feed in tariff structure. For the futures series the volatility between the markets is broadly similar.

[Figure 1 here]

[Table 2 here]

The coefficients from the GARCH $(1,1)$ model for electricity are quite different from those typically found at weekly and monthly frequencies for other financial or energy assets. For example, volatility persistence is very high not only at the weekly but also at the monthly frequencies. Only the Nordpool series displays a volatility persistence structure that is similar to other assets with persistence declining as the time horizon lengthens whereas for both APXUK and PHELIX the volatility persistence remains very high at weekly and monthly frequencies. These results are in line with the stylised facts for electricity markets and are similar to those found by other studies such as Gianfreda (2010). We now go on to look at the results from the hedging models.

\subsection{Optimal Hedges}

Figure 2 presents the OHR's for each of the three markets examined for both weekly and monthly data. The first thing to note is the volatility of the CCGARCH OHR's for each market but especially for the weekly hedges. For example the Phelix market has an OHR in excess of 3 on a number of occasions and on one occasion it goes as high as 8.9.

[Figure 2 here]

For monthly data the time-varying hedges are somewhat lower but are still large in comparison to those obtained from other assets which typically have OHRs in the range 0.5 to 1.5 (Cotter and Hanly, 2012). The second thing to note is the difference between the 
OHR's for the different markets. For example at the weekly (monthly) frequency the OLS based OHR's are $0.56(0.89)$ for Nordpool, 1.02 (0.72) for APXUK and 0.94 (0.92) for Phelix. These results reflect the different volatility and correlation dynamics between spot and futures for the different markets.

\subsection{Hedging Effectiveness}

In this paper we sought to establish the hedging effectiveness of futures hedging strategies for electricity market participants in Europe and to make inter market comparisons to see whether any significant differences emerged. Accordingly, Table 3 shows in-sample results for the three electricity markets we examine; Nordpool, APXUK and Phelix. Two risk measures, Variance and $\mathrm{VaR}$ are presented together with the percentage reduction in those risk measures using two frequencies, Weekly and Monthly ${ }^{5}$.

From Table 3, the standout result is that hedging effectiveness is quite low for each of the electricity markets and especially so at the weekly frequency. Taking the best performing model for each market for example, hedging effectiveness as measured by variance reduction ranges from $8.03 \%$ for Phelix to $8.19 \%$ for APXUK and $8.77 \%$ for the best performer which is Nordpool. Using the $\mathrm{VaR}$ criterion, the results are even poorer with reductions ranging from $4.11 \%$ (Phelix) to $4.52 \%$ (Nordpool).To put this in economic terms, for an exposure in the electricity market of $€ 1$ million, for the best performer which is Nordpool, hedging would reduce the value at risk from $€ 395,288$ to $\$ 377,892$ - a reduction of just $€ 17,396$. These results are worse than those reported by Bystrom (2003) who found weekly hedging efficiency of about $17 \%$ for the Nordpool market. However we examine a much larger time period and two additional markets. Moving on to look at hedges within a monthly time horizon, the results are significantly better, with hedging effectiveness for the best performing model ranging from $17.77 \%$ for the APXUK hedges to $24.02 \%$ for Phelix and $27.37 \%$ for Nordpool which is again the best performing market. VaR reductions are also improved but are still quite low. For example the best hedging performance using VaR is in the Nordpool market (15.39\%) while the worst is APXUK (9.02\%). The results from VaR which is a tail specific measure indicate that the volatility and non-normality of electricity price data presents a particular challenge in terms of obtaining a good hedging outcome. These findings indicate that electricity hedges perform very poorly when compared with the broader hedging literature for which hedging efficiency in the range $50 \%-90 \%$ is not uncommon.

\footnotetext{
${ }^{5}$ We also estimated but do not present detailed results for Daily hedges as hedging effectiveness was extremely poor in all cases averaging about $1.3 \%$ across all assets ${ }^{5}$. This is comparable to results for daily hedges found by Zanotti, Gabbi and Geranio (2010).
} 
[Table 3 here]

We also compare the hedging performance of the OLS and CCGARCH models using a bootstrap process (Efron, 1979) whereby we resampled the hedged returns from each portfolio to facilitate t-tests of the differences between the performances of the different hedging models. The models generated significantly different performance for APXUK and Phelix at the weekly frequency and for Nordpool and Phelix at the monthly frequency. The differences were especially marked for the Phelix market which yielded very large performance differentials depending on the model used to estimate the OHR. In terms of the best model, the OLS was the better performer in all cases at the weekly frequency and also performed best in 50\% of cases at the monthly frequency. In those cases where the CCGARCH model outperformed the OLS model, there was a significant difference only in the case of the Nordpool hedge at the monthly frequency. The relatively poor performance of the CCGARCH model may relate to an inability of GARCH models to handle large and frequent jumps in the basis as are typical for electricity markets. This has been found by other studies for even less volatile series such as Oil (Alexander, Prokopczuk and Sumawong, 2013) and Equities (Lee and Yoder, 2007). From these results we conclude that an OLS model is perfectly adequate in that it provides the best chance of obtaining good hedging effectiveness.

Next, we formally compare the performance of the different markets in Table 4 using both Variance and VaR metrics on a model by model basis. Taking Monthly data as an example and using the Variance as our risk metric we can see that there is a significant difference of $7.13 \%$ (t-stat 8.78 ) between the hedging performance of the Nordpool and APXUK markets using the OLS model. Overall we make 24 comparisons. Of these there are significant differences between the hedging performances of the different electricity markets in $67 \%$ of cases. This indicates that futures tend to work better as a hedging tool depending on the electricity market they are based on.

[Table 4 here]

\subsection{Rolling Window Portfolio Results}

Our initial estimates from the OLS and CCGARCH models for hedging effectiveness indicated relatively poor performance. To investigate this further we generated a series of rolling window OHR's together with a time dependent hedging effectiveness measure to allow us to track hedging performance in the different markets through different time periods. 
Results for this estimation are presented in Table 5 and in Figure 3. The most noteworthy point is that there is a large variation in the hedging effectiveness across time. For certain time periods, hedges are quite effective and in some cases comparable to other energy markets. This is particularly the case for the monthly hedging frequency and for the Nordpool market which shows a maximum \% reduction in the variance of $82.9 \%$. For APXUK it is $72.3 \%$ and for Phelix it is $64.3 \%$.

[Table 5 here]

[Figure 3 here]

These figures would constitute reasonably effective hedges for any asset, however as shown in Figure 3, there are also periods for which there is no appreciable benefit to hedging. It would appear therefore that hedges only seem to be effective for short time periods during which the spot and futures returns are highly correlated. However, the fundamentally volatile nature of electricity markets means that this is a relatively rare occurrence and of course is difficult to predict.

Table 6 reports the out-of-sample results which are based on a one step-ahead forecast of the OHR's as described in section 4. As for the in-sample results, the hedging effectiveness is generally low. We can also see that in some cases hedging yields an increase in risk as compared with a no-hedge scenario. For example, a CCGARCH hedge at the weekly frequency marginally increases the variance of a Nordpool position from $1.60 \%$ to $1.67 \%$. Also the out-of-sample results confirm the finding that monthly hedges significantly outperform weekly hedges. Finally the results show that the hedging efficiency for the in sample period is generally higher than for the out-of-sample period. Across all markets, models and both risk metrics, the in-sample average hedging effectiveness is $1.6 \%$ higher at the weekly frequency and $4.4 \%$ higher at the monthly frequency. Given the results of our rolling window portfolio estimation which showed a wide variation in hedging effectiveness, we attribute this difference to the time period examined.

[Table 6 here] 


\section{CONCLUSION}

We examine the volatility characteristics of three of Europe's most deeply established electricity markets and estimate risk management strategies for those markets using futures hedging. We look at two different hedging horizons and apply both constant and time varying approaches. Using a two sided risk measure - the variance, as well as a downside risk measure - VaR to evaluate the hedging effectiveness of these hedge strategies. We also track the conditional hedging performance over a time period spanning 2005 - 2014 which allows us to make a comprehensive comparison of the relative hedging performance of the different markets through different market conditions.

Our findings indicate that there are significant differences between the volatility characteristics, OHR's and the hedging performance for the different energy markets we examine. We also find that the time period and underlying volatility characteristics of the electricity market have a very significant impact on the hedging efficacy. Of particular note is the poor hedging performance of electricity hedges for all markets at the weekly frequency. The implication of this is that electricity market participants may struggle to reduce their exposure using futures hedging over short time horizons. The relatively poor performance of electricity futures as risk management tools raises questions as to the role and utility of electricity futures markets. 


\section{REFERENCES}

Alexander, C., M. Prokopczuk and A. Sumawong. (2013). "The (de)merits of minimumvariance hedging: Application to the crack spread.” Energy Economics 36: 698-707.

Alexander, C., and A. Barbossa. (2008). "Hedging index exchange traded funds." Journal of Banking \& Finance 32 (2): 326-337.

Bollerslev, T. (1986). "Generalized autoregressive conditional heteroscedasticity." Journal of econometrics 31 (3): 307-327.

Bollerslev, T. (1990). "Modeling the coherence in short-run nominal exchange rates: A multivariate generalized ARCH model." Review of Economics and Statistics 72: 498-505.

Botterud, A. T. Kristiansen, and M. Ilic. (2010). "The relationship between spot and futures prices in the Nord Pool electricity market.” Energy Economics 32 (5): 967-978.

Brinkmann, E., and R. Rabinovitch. (1995). "Regional limitations on the hedging effectiveness of natural gas futures.” The Energy Journal 16:113-124.

Chang, C. M. McAleer, and R. Tansuchat. (2011). "Crude oil hedging strategies using dynamic multivariate GARCH.” Energy Economics, 33 (5): 912 - 923.

Chen, F., and C. Sutcliffe. (2012). "Better cross hedges with composite hedging? Hedging equity portfolios using financial and commodity futures." European Journal of Finance, 18 (6): $575-595$.

Cotter, J., and J. Hanly. (2012). "Hedging Effectiveness under conditions of asymmetry." European Journal of Finance, 18 (2): 135-147.

Ederington, L. (1979). “The hedging performance of the new futures markets." Journal of Finance, 34 (1): 157 - 170.

Engle, R. F. (2002). "Dynamic Conditional Correlation - A Simple Class of Multivariate GARCH Models."’ Journal of Business and Economic Statistics, 20, 339-350. 
Efron, B. (1979). "Bootstrap methods: Another look at the Jack-knife." The Annals of Statistics 7: 1-26.

Fraser, P., and A. Mckaig. (2000). "UK metal and energy basis variation and a common source of risk: a note". International Journal of Finance and Economics 5(2): 155-164.

Frestad, D. (2012). "Liquidity and dirty hedging in the Nordic electricity market." Energy Economics 34 (5): 1341 - 1355.

Gianfreda, A. (2010). "Volatility and Volume Effects in European Electricity Spot Markets." Economic Notes. 39 (1-2): 47-63.

Kanas, A. (2009). "Regime switching in stock index and futures markets: a note on the NIKKEI evidence". International Journal of Finance and Economics 14 (4): 394-399.

Kroner, K.F., and J. Sultan. (1993). "Time-varying distributions and dynamic hedging with foreign currency futures.” Journal of Financial and Quantitative Analysis 28 (4): 535-551.

Röthig, A. (2011). “On speculators and hedgers in currency futures markets: who leads whom?. International Journal of Finance and Economics 16 (1): 63 - 69.

Sanda, G., E. Olsen, and S. Fleten. (2013). "Selective hedging in hydro-based electricity companies." Energy Economics 40 (1): 326-338.

Tanlapco, E., J. Lawarrée, and C. Liu. (2002). "Hedging With Futures Contracts in a Deregulated Electricity Industry.” IEEE Power Engineering Review, 7 (22): 577 - 582.

Wickens, S., and J. Wimschulte. (2007). "The pricing of electricity futures: evidence from the European energy exchange." Journal of Futures Markets 27 (4): 387-410.

Wu, F., Z. Guan, and R. Myers. (2011). "Volatility spillover effects and cross hedging in corn and crude oil futures.” Journal of Futures Markets 31(11): 1052-1075.

Xiao, Y., D. Colwell, and R. Bhar. (2014). "Risk Premium in Electricity Prices: Evidence from the PJM Market.” Journal of Futures Markets 35 (8): 776-793. 
Zanotti, G., G. Gabbi, and M. Geranio, (2010). "Hedging with futures: Efficacy of GARCH correlation models to European electricity markets." Journal of International Financial $\begin{array}{llllll}\text { Markets, } & \text { Institutions } & \text { and } & \text { Money. } & 20 & \text { (2): }\end{array}$ 
Table 1 Descriptive Statistics

\begin{tabular}{|c|c|c|c|c|c|c|c|c|c|c|c|c|c|}
\hline & \multirow[t]{2}{*}{ Index } & \multirow{2}{*}{$\frac{\text { Mean }}{\%}$} & \multirow{2}{*}{$\frac{\text { Std Dev }}{\%}$} & \multirow[t]{2}{*}{ Skewness } & \multirow[t]{2}{*}{ Kurtosis } & \multirow[t]{2}{*}{ JB } & \multirow[t]{2}{*}{ LM } & \multicolumn{4}{|c|}{ STATIONARITY } & \multicolumn{2}{|c|}{ Correlation } \\
\hline & & & & & & & & ADF & $\mathbf{P P}$ & KPSS & & Price & Return \\
\hline NORDPOOL & & & & & & & & & & CONSTANT & TREND & & \\
\hline \multirow[t]{2}{*}{ DAILY } & Spot & 0.0063 & 7.87 & $0.30 *$ & $11.20 *$ & $13730.8^{*}$ & $212.8^{*}$ & $-24.1 *$ & $-53.7 *$ & 0.010 & $0.008 *$ & 0.900 & 0.09 \\
\hline & Futures & 0.0052 & 3.51 & $1.27 *$ & $17.08 *$ & $32541.9 *$ & 5.0 & $-23.6^{*}$ & $-48.1 *$ & $0.032 *$ & $0.022 *$ & & \\
\hline \multirow[t]{2}{*}{ WEEKLY } & Spot & 0.0314 & 15.53 & $-0.28 *$ & $19.11 *$ & $7976.5^{*}$ & $84.2 *$ & $-9.2 *$ & $-26.0^{*}$ & $0.016^{*}$ & $0.012 *$ & 0.894 & 0.28 \\
\hline & Futures & 0.0262 & 8.19 & $0.34 *$ & $3.52 *$ & $280.0^{*}$ & $32.3 *$ & $-26.0 *$ & $-24.1 *$ & $0.039^{*}$ & $0.026^{*}$ & & \\
\hline \multirow[t]{2}{*}{ MONTHLY } & Spot & 0.5776 & 29.34 & $0.38 *$ & $11.22 *$ & $638.1^{*}$ & $33.9 *$ & $-5.8^{*}$ & $-16.6^{*}$ & $0.057 *$ & $0.028^{*}$ & 0.8957 & 0.49 \\
\hline & Futures & 0.0702 & 15.83 & $-0.38^{*}$ & $2.12 *$ & $25.5^{*}$ & 7.2 & $-5.8 *$ & $-10.9 *$ & $0.033^{*}$ & $0.030 *$ & & \\
\hline \multicolumn{14}{|l|}{ APXUK } \\
\hline \multirow[t]{2}{*}{ DAILY } & Spot & 0.0268 & 15.47 & $0.32 *$ & $6.39 *$ & $4496.8^{*}$ & $149.2^{*}$ & $-31.7 *$ & $-78.6^{*}$ & $0.009^{*}$ & $0.005^{*}$ & 0.8020 & 0.16 \\
\hline & Futures & 0.0201 & 2.75 & $2.17 *$ & $24.76 *$ & $68997.8^{*}$ & $47.3^{*}$ & $-23.8^{*}$ & $-48.1 *$ & $0.051 *$ & $0.043^{*}$ & & \\
\hline \multirow[t]{2}{*}{ WEEKLY } & Spot & 0.1339 & 20.99 & $-0.31 *$ & $5.38 *$ & $640.5^{*}$ & $45.8 *$ & $-14.5^{*}$ & $-36.6^{*}$ & $0.029^{*}$ & $0.015^{*}$ & 0.8010 & 0.28 \\
\hline & Futures & 0.1003 & 6.09 & $0.26^{*}$ & $4.93 *$ & $536.7 *$ & $54.3 *$ & $-7.5^{*}$ & $-22.8^{*}$ & $0.043^{*}$ & $0.036^{*}$ & & \\
\hline \multirow[t]{2}{*}{ MONTHLY } & Spot & 1.8892 & 25.72 & $0.54 *$ & $6.42 *$ & $213.6^{*}$ & 14.0 & $-4.3^{*}$ & $-16.7 *$ & $0.263^{*}$ & $0.055^{*}$ & 0.8250 & 0.38 \\
\hline & Futures & 0.4499 & 13.18 & $-0.66^{*}$ & $3.88 *$ & $84.5^{*}$ & $33.7 *$ & $-4.9 *$ & $-8.1 *$ & $0.047^{*}$ & $0.033^{*}$ & & \\
\hline \multicolumn{14}{|l|}{ EEX PHELIX } \\
\hline \multirow[t]{2}{*}{ DAILY } & Spot & 0.0151 & 23.33 & -0.05 & $13.97 *$ & $21312.5^{*}$ & $575.3^{*}$ & $-31.8^{*}$ & $-84.0 *$ & $0.004^{*}$ & $0.003^{*}$ & 0.7110 & 0.07 \\
\hline & Futures & 0.0029 & 3.32 & $2.07 *$ & $38.43 *$ & $163061.6^{*}$ & 9.2 & $-22.8^{*}$ & $-49.6^{*}$ & $0.042 *$ & $0.019^{*}$ & & \\
\hline \multirow[t]{2}{*}{ WEEKLY } & Spot & 0.0756 & 29.34 & $-1.17 *$ & $11.93 *$ & $3227.3^{*}$ & $59.7 *$ & $-14.4^{*}$ & $-40.6^{*}$ & $0.015^{*}$ & $0.011 *$ & 0.7431 & 0.29 \\
\hline & Futures & 0.0146 & 7.56 & $0.49 *$ & $5.21 *$ & $613.2 *$ & $28.0 *$ & $-11.1^{*}$ & $-23.4 *$ & $0.044^{*}$ & $0.020^{*}$ & & \\
\hline \multirow[t]{3}{*}{ MONTHLY } & Spot & 1.6047 & 36.73 & $0.27 *$ & $4.31 *$ & $95.0^{*}$ & $31.5^{*}$ & $-6.3 *$ & $-19.4^{*}$ & $0.341 *$ & $0.054^{*}$ & 0.7568 & 0.41 \\
\hline & Futures & 0.1281 & 15.41 & -0.12 & 0.24 & $0.6^{*}$ & 12.7 & $-4.9 *$ & $-12.0 *$ & $0.058^{*}$ & $0.030 *$ & & \\
\hline & $1 \%$ C.V & & & & & 9.21 & 13.23 & -3.43 & -3.43 & 0.74 & 0.22 & & \\
\hline
\end{tabular}




\begin{tabular}{|c|c|c|c|c|c|c|}
\hline Market & Frequency & & $\omega$ & $\alpha$ & $\boldsymbol{\beta}$ & $\alpha+\beta$ \\
\hline & & & & & & Volatility \\
\hline & & & & & & Persistence \\
\hline \multirow[t]{6}{*}{ NORDPOOL } & DAILY & Spot & 0.0004 & 0.331 & 0.653 & 0.984 \\
\hline & & Futures & 0.0003 & 0.068 & 0.907 & 0.975 \\
\hline & WEEKLY & Spot & 0.0021 & 0.329 & 0.610 & 0.939 \\
\hline & & Futures & 0.0017 & 0.236 & 0.525 & 0.761 \\
\hline & MONTHLY & Spot & 0.0511 & 0.212 & 0.105 & 0.317 \\
\hline & & Futures & 0.0156 & 0.382 & 0.003 & 0.385 \\
\hline \multirow[t]{6}{*}{ APXUK } & DAILY & Spot & 0.0014 & 0.241 & 0.726 & 0.967 \\
\hline & & Futures & 0.0003 & 0.273 & 0.718 & 0.991 \\
\hline & WEEKLY & Spot & 0.0049 & 0.410 & 0.537 & 0.947 \\
\hline & & Futures & 0.0001 & 0.142 & 0.841 & 0.983 \\
\hline & MONTHLY & Spot & 0.0031 & 0.173 & 0.782 & 0.955 \\
\hline & & Futures & 0.0005 & 0.296 & 0.701 & 0.997 \\
\hline \multirow[t]{6}{*}{ EEX PHELIX } & DAILY & Spot & 0.0029 & 0.292 & 0.695 & 0.987 \\
\hline & & Futures & 0.0004 & 0.046 & 0.560 & 0.606 \\
\hline & WEEKLY & Spot & 0.0118 & 0.602 & 0.394 & 0.996 \\
\hline & & Futures & 0.0002 & 0.066 & 0.909 & 0.975 \\
\hline & MONTHLY & Spot & 0.0010 & 0.128 & 0.823 & 0.951 \\
\hline & & Futures & 0.0011 & 0.129 & 0.824 & 0.953 \\
\hline
\end{tabular}

Note: Volatility is measured as the unconditional volatility estimated using $\omega_{i} / 1(-\alpha-\beta)$ from a univariate GARCH $(1,1)$ process as in equation : $h_{i t}=\omega_{i}+\sum_{j=1}^{r} \alpha_{i j} \varepsilon_{i}^{2},_{t-j}+\sum_{j=1}^{s} \beta_{i j} h_{i, t-j}$. The sum of $\alpha+\beta$ measures volatility persistence. The model was run constraining $\alpha+\beta \leq 1$ which is equivalent to an IGARCH specification to avoid explosive volatility 
Table 3: In Sample Hedging

\begin{tabular}{|c|c|c|c|c|c|c|c|}
\hline & & 1 & 2 & 3 & 4 & 5 & 6 \\
\hline & & \multicolumn{3}{|c|}{ WEEKLY } & \multicolumn{3}{|c|}{ MONTHLY } \\
\hline & & NO HEDGE & OLS & CCGARCH & NO HEDGE & OLS & CCGARCH \\
\hline \multirow[t]{4}{*}{ NORDPOOL } & VARIANCE & $2.88 \%$ & $2.63 \%$ & $2.64 \%$ & $10.20 \%$ & $7.69 \%$ & $7.41 \%$ \\
\hline & VaR & $-€ 395,288$ & $-€ 377,439$ & $-€ 377,892$ & $-€ 742,901$ & $-€ 646,834$ & $-€ 628,562$ \\
\hline & $\%$ Variance Reduction & $0.00 \%$ & $8.77 \%^{\wedge}$ & $8.40 \%^{\wedge}$ & $0.00 \%$ & $24.65 \% *$ & $27.37 \%$ \\
\hline & $\%$ VaR Reduction & $0.00 \%$ & $4.52 \%{ }^{\lambda}$ & $4.40 \%^{\lambda}$ & $0.00 \%$ & $12.93 \% *$ & $15.39 \%$ \\
\hline \multirow[t]{4}{*}{ APXUK } & VARIANCE & $5.36 \%$ & $4.92 \%$ & $5.03 \%$ & $6.76 \%$ & $5.58 \%$ & $5.56 \%$ \\
\hline & VaR & $-€ 538,258$ & $-€ 515,979$ & $-€ 524,230$ & $-€ 603,683$ & $-€ 549,238$ & $-€ 551,779$ \\
\hline & $\%$ Variance Reduction & $0.00 \%$ & $8.19 \% *^{\lambda}$ & $6.17 \%^{\wedge}$ & $0.00 \%$ & $17.51 \%$ & $17.77 \%$ \\
\hline & $\%$ VaR Reduction & $0.00 \%$ & $4.14 \% *^{\lambda}$ & $2.61 \%^{\wedge}$ & $0.00 \%$ & $9.02 \%$ & $8.60 \%$ \\
\hline \multirow[t]{4}{*}{ PHELIX } & VARIANCE & $7.77 \%$ & $7.15 \%$ & $7.79 \%$ & $9.79 \%$ & $7.44 \%$ & $9.81 \%$ \\
\hline & VaR & $-€ 648,492$ & $-€ 621,841$ & $-€ 650,505$ & $-€ 735,341$ & $-€ 641,252$ & $-€ 720,118$ \\
\hline & $\%$ Variance Reduction & $0.00 \%$ & $8.03 \% *^{\lambda}$ & $-0.19 \%$ & $0.00 \%$ & $24.02 \% *$ & $-0.15 \%$ \\
\hline & \% VaR Reduction & $0.00 \%$ & $4.11 \% * \dagger$ & $-0.31 \%$ & $0.00 \%$ & $12.80 \% *$ & $2.07 \%$ \\
\hline
\end{tabular}

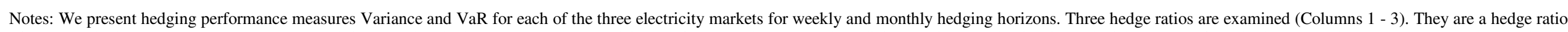

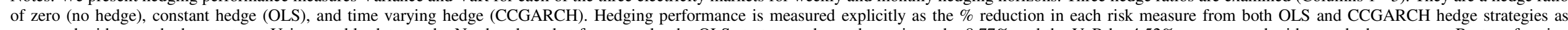

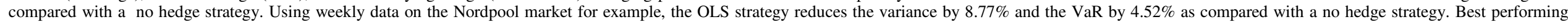

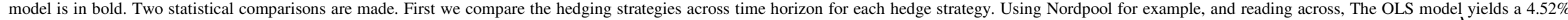

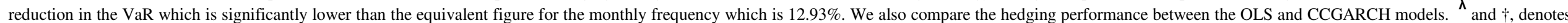

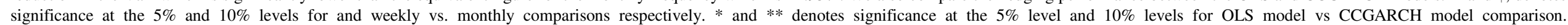


Table 4: Hedging Performance Comparison

\begin{tabular}{|c|c|c|c|c|c|c|c|}
\hline \multirow{14}{*}{ 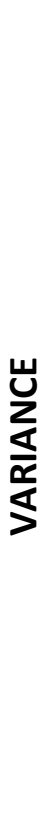 } & & \multicolumn{3}{|c|}{$\begin{array}{c}\text { WEEKLY } \\
\text { OLS }\end{array}$} & \multicolumn{3}{|c|}{$\begin{array}{c}\text { MONTHLY } \\
\text { OLS }\end{array}$} \\
\hline & & NORDPOOL & APXUK & PHELIX & NORDPOOL & APXUK & PHELIX \\
\hline & \multirow[t]{2}{*}{ NORDPOOL } & $0.00 \%$ & $0.58 \%$ & $0.74 \%$ & $0.00 \%$ & $7.13 \% *$ & $0.63 \%$ \\
\hline & & & $(1.23)$ & (1.59) & & (8.78) & $(0.64)$ \\
\hline & \multirow[t]{2}{*}{ APXUK } & & $0.00 \%$ & $0.16 \%$ & & $0.00 \%$ & $6.50 \% *$ \\
\hline & & & & $(0.36)$ & & & (7.78) \\
\hline & \multirow[t]{3}{*}{ PHELIX } & & & $0.00 \%$ & & & $0.00 \%$ \\
\hline & & $\mathrm{CC}$ & GARCH & & $\mathrm{CCC}$ & $\mathrm{ARCH}$ & \\
\hline & & NORDPOOL & APXUK & PHELIX & NORDPOOL & APXUK & PHELIX \\
\hline & \multirow[t]{2}{*}{ NORDPOOL } & $0.00 \%$ & $2.23 \% *$ & $8.59 \% *$ & $0.00 \%$ & $9.60 \% *$ & $27.52 \% *$ \\
\hline & & & $(5.55)$ & (32.91) & & $(12.42)$ & $(51.35)$ \\
\hline & \multirow[t]{2}{*}{ APXUK } & & $0.00 \%$ & $6.36 \% *$ & & $0.00 \%$ & $17.92 \% *$ \\
\hline & & & & (26.10) & & & (39.66) \\
\hline & \multirow[t]{3}{*}{ PHELIX } & & & $0.00 \%$ & & & $0.00 \%$ \\
\hline \multirow{14}{*}{ 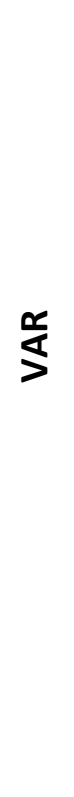 } & & \multicolumn{3}{|c|}{ OLS } & \multicolumn{3}{|c|}{ OLS } \\
\hline & & NORDPOOL & APXUK & PHELIX & NORDPOOL & APXUK & PHELIX \\
\hline & \multirow[t]{2}{*}{ NORDPOOL } & $0.00 \%$ & $0.38 \%$ & $0.41 \%$ & $0.00 \%$ & $3.91 \% *$ & $0.14 \%$ \\
\hline & & & $(0.32)$ & $(0.33)$ & & $(3.30)$ & $(0.07)$ \\
\hline & \multirow[t]{2}{*}{ APXUK } & & $0.00 \%$ & $0.03 \%$ & & $0.00 \%$ & $3.78 \% * *$ \\
\hline & & & & $(0.02)$ & & & (1.87) \\
\hline & \multirow[t]{3}{*}{ PHELIX } & & & $0.00 \%$ & & & $0.00 \%$ \\
\hline & & $\mathrm{CC}$ & GARCH & & $\mathrm{CCC}$ & $\mathrm{ARCH}$ & \\
\hline & & NORDPOOL & APXUK & PHELIX & NORD & APXUK & PHELIX \\
\hline & \multirow[t]{2}{*}{ NORDPOOL } & $0.00 \%$ & $1.79 \% *$ & $4.71 \% *$ & $0.00 \%$ & $6.79 \% *$ & $13.32 \% *$ \\
\hline & & & $(2.22)$ & $(5.73)$ & & (7.39) & (11.55) \\
\hline & \multirow[t]{2}{*}{ APXUK } & & $0.00 \%$ & $2.92 \% *$ & & $0.00 \%$ & $6.53 \% *$ \\
\hline & & & & (3.53) & & & $(5.61)$ \\
\hline & PHELIX & & & $0.00 \%$ & & & $0.00 \%$ \\
\hline
\end{tabular}

Note: Table 4 shows a comparison between the hedging performance for the different electricity markets. Taking Monthly data for example, there is a significant difference $(7.13 \%)$ between the hedging performance of the OLS model for the Nordpool and the APXUK markets. T-statistics are in parentheses. ${ }^{*},{ }^{* *}$ denotes significance at the $5 \%$ and $10 \%$ levels respectively. 
Table 4: Hedging Effectiveness of Portfolio of Rolling Window OHR's

(1)

NORDPOOL

WEEKLY

MEAN

MIN

MAX

STDEV

MONTHLY

MEAN

MIN

MAX

STDEV

$13.3 \%$

$0.1 \%$

$43.8 \%$

$11.2 \%$

$39.2 \%$

$0.0 \%$

$82.9 \%$

$21.4 \%$
(2)

APXUK

(3)

PHELIX

$20.6 \%$

$24.3 \%$

$0.0 \%$

$1.0 \%$

$72.3 \%$

$64.3 \%$

$19.8 \%$

$14.3 \%$

Summary statistics of the hedging effectiveness of a portfolio of hedges estimated using a rolling window based on variance minimisation. 
Table 5: Out-of-Sample Hedging

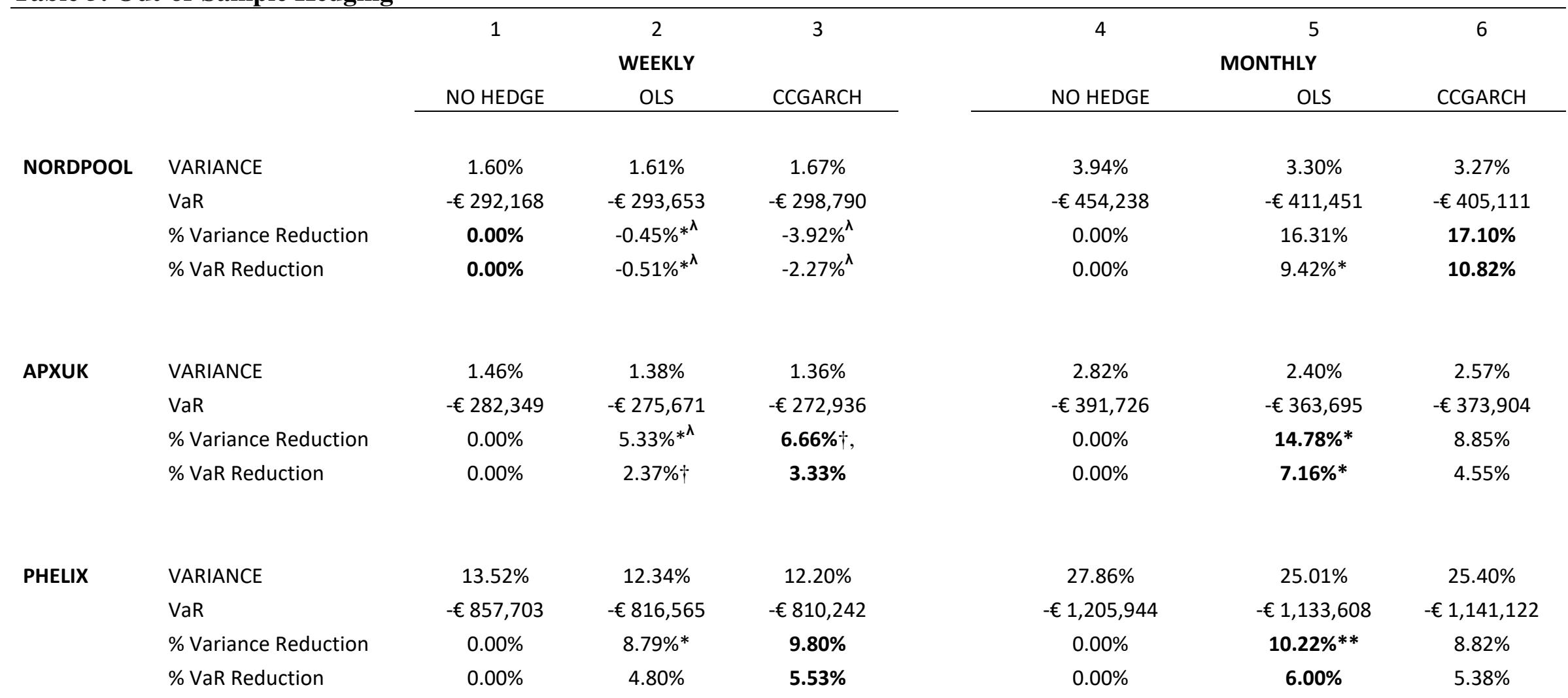

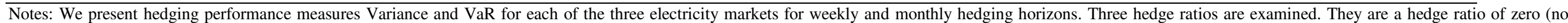

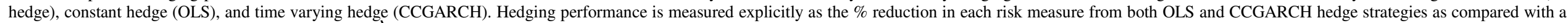

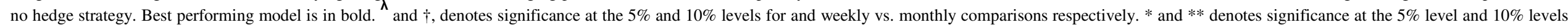
for OLS model vs CCGARCH model comparison. 

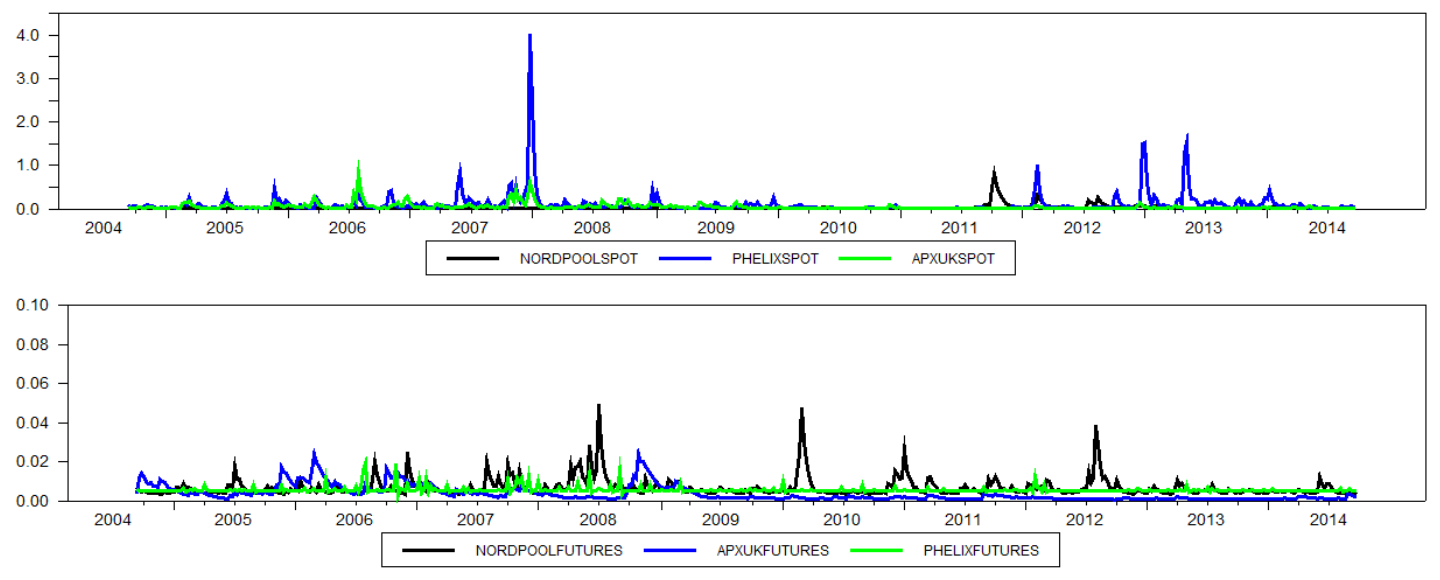

Fig1. Volatility of NORDPOOL, APXUK AND PHELIX Electricity Spot and Futures using Weekly data. Note the Spot and Futures are to difference scales. 
WEEKLY

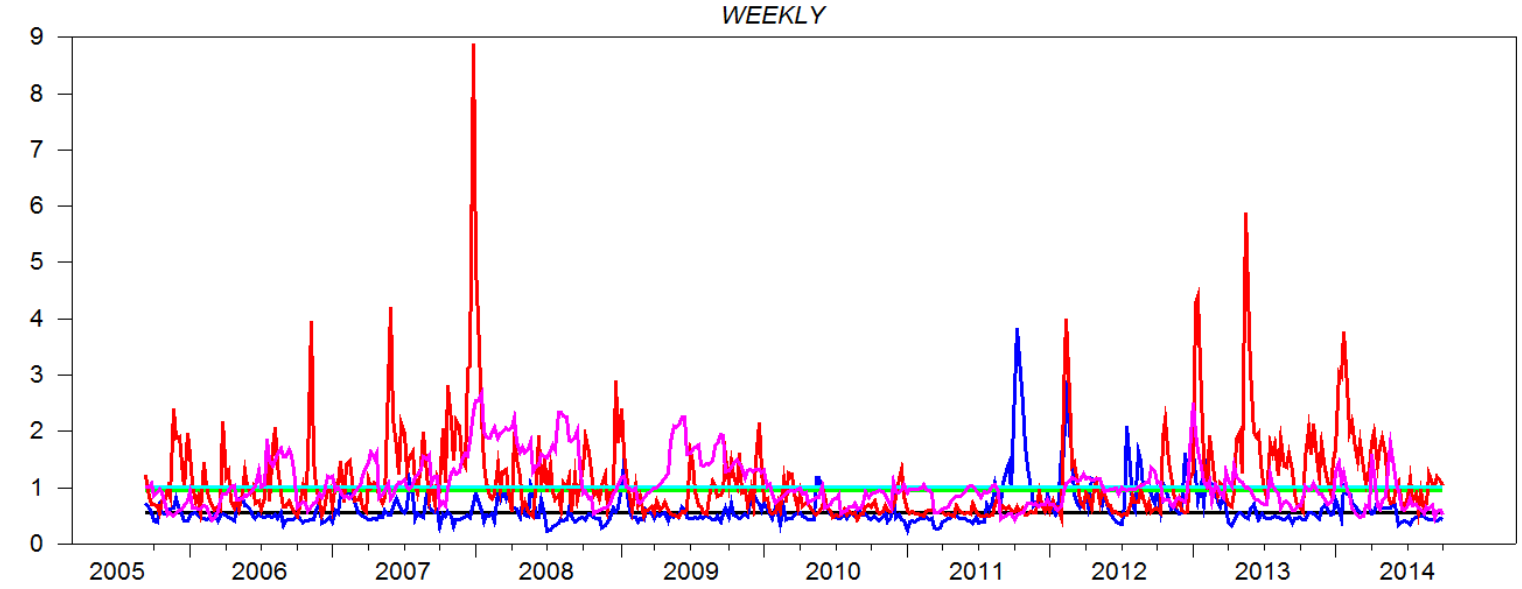

MONTHLY

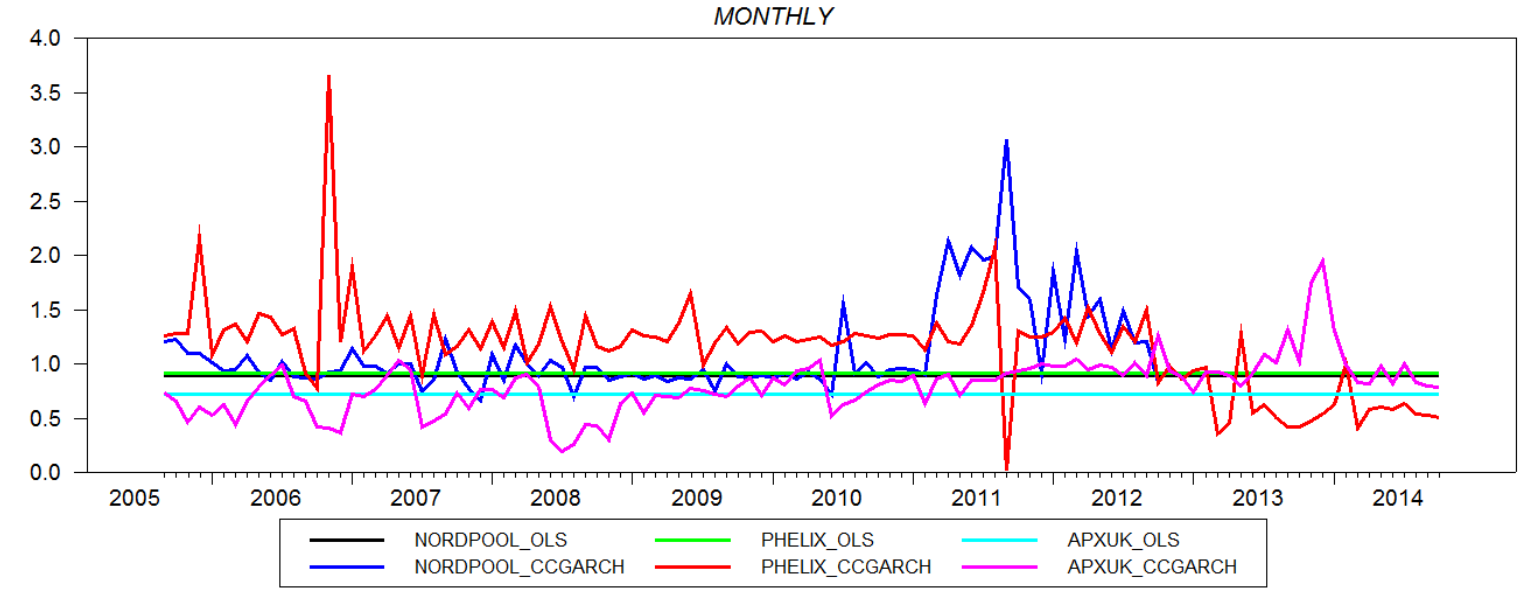

Fig 2. Optimal Hedge Ratios, OLS AND CCGARCH for NORDPOOL, APXUK and PHELIX markets. 
WEEKLY

ROLLWNG WWOOOWOHA

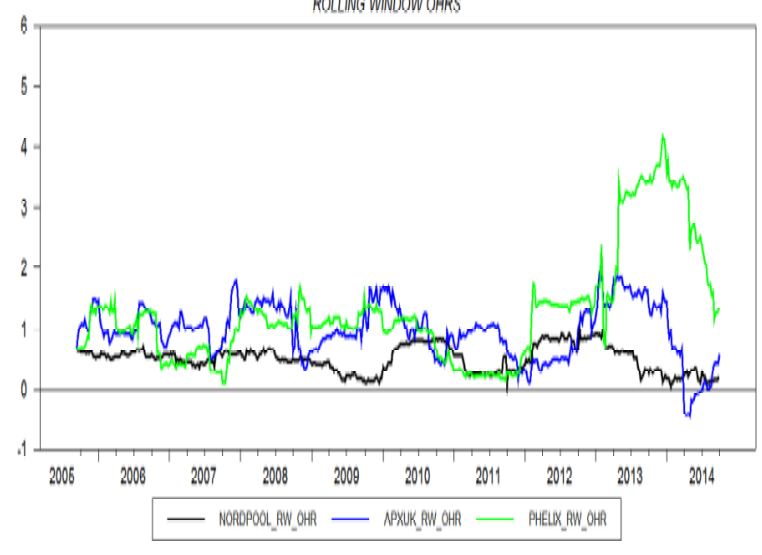

HEDGNG EFFECTNENESS

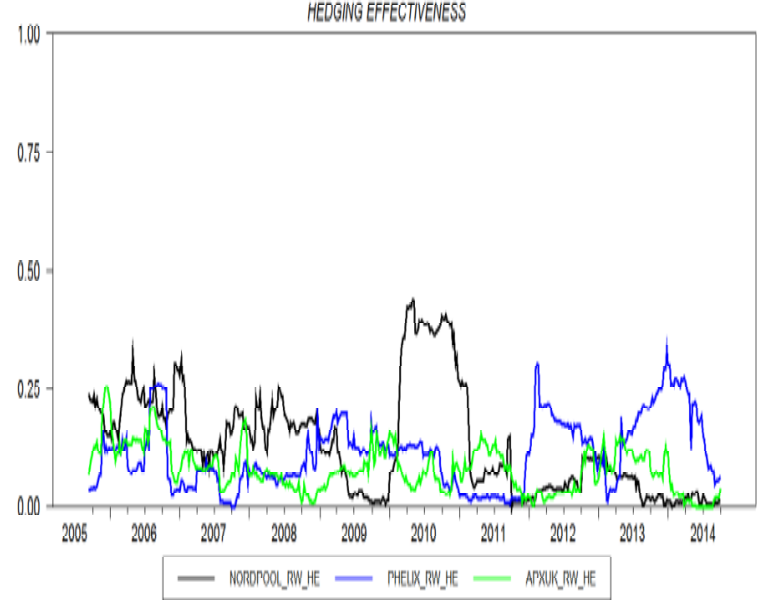

MONTHLY

ROLLNG WNDOW OHRS

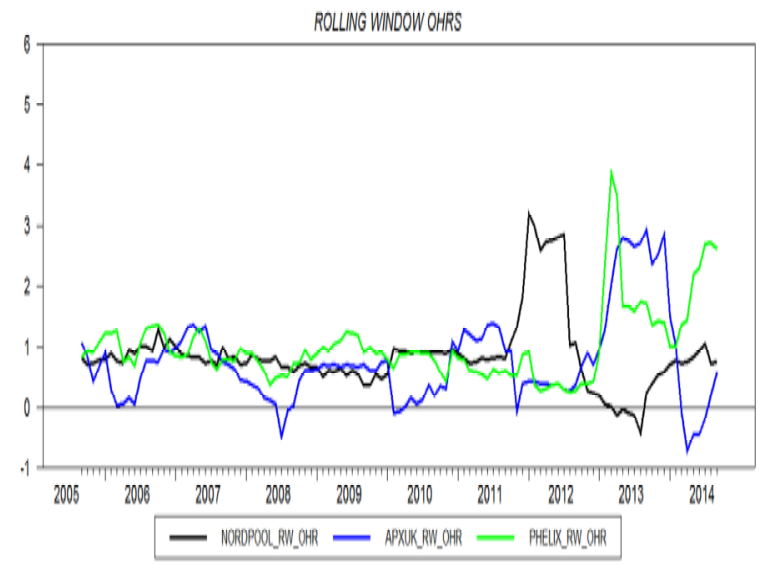

HEDGNG EFFECTNENESS

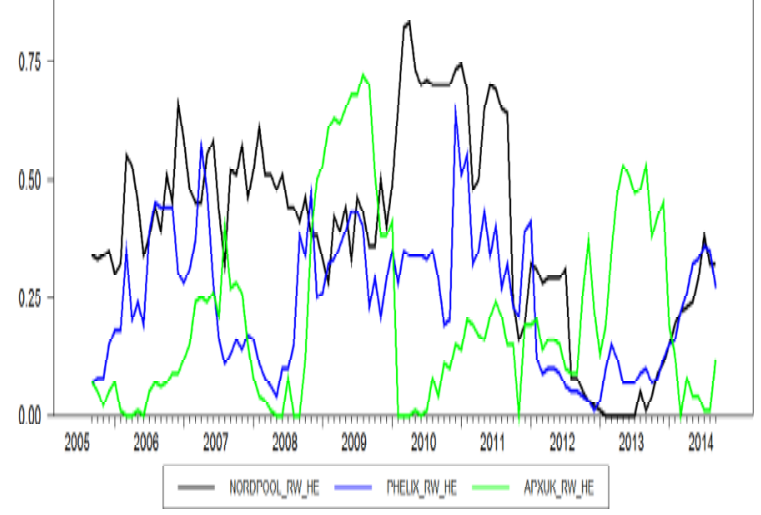


Fig.3 Time Varying Hedging Rolling Window Portfolio OHR's and Hedging Effectiveness. 